\title{
PENERAPAN LATIHAN GOAL SETTING DAN VISUALISASI TERHADAP PENINGKATAN MOTIVASI PEMAIN DAKSINA FUTSAL ACADEMY
}

\author{
Daniel Oktariza Efendi \\ Juriana Dan Bambang Sujiono
}

\author{
Fakultas Ilmu Olahraga Universitas Negeri Jakarta \\ Email:danieloktariza@gmail.com, \\ juriana@unj.ac.iddan bsujiono@unj.ac.id
}

\begin{abstract}
ABSTRAK
Tujuan penelitian ini adalah untuk mengetahui efektifitas latihan goal setting dan visualisasi terhadap peningkatan motivasi pemain Daksina Futsal Academy. Penelitian ini dilaksanakan di Daksina Futsal Academy dan metode yang dipergunakan dalam penelitian ini adalah metode eksperimen one group dengan teknik Tes awal, Perlakuan, dan akhir (pre-test post-test). Penelitian ini diikuti oleh 30 orang sample pemain Daksina Futsal Academy. Mereka diminta menjawab butir-butir pernyataan angket penelitian tentang motivasi setelah itu mengikuti materi pelatihan goal setting dan visualisasi selama 5 sesi lalu diberikan kembali angket untuk melakukan tes akhir.

Disampaikan tentang nilai rata-rata $(\bar{X})$ dari hasil yang didapatkan pada tes awal 85,23 dan pada tes akhir 92,87. Dari rata-rata mengenai tes awal dan tes akhir Motivasi pemain Daksina Futsal Academy, menunjukan adanya peningkatan hasil yang didapat. Dari hasil analisis data diperoleh selisih rata-rata $\left(\mathrm{M}_{\mathrm{D}}\right)$-7,63 dengan standar deviasi perbedaan $\left(\mathrm{SD}_{\mathrm{D}}\right) 6,80$ standar error perbedaan rata-rata $\left(\mathrm{SE}_{\mathrm{MD}}\right) 1,29$ dalam perhitungan selanjutnya diperoleh nilai thitung sebesar $-6,05$ dan nilai t-tabel dengan derajat kebebasan (n-1) dan taraf signifikan $\alpha=$ 0,05 didapat sebesar 2,045. Nilai $\mid \mathrm{t}$-hitung $\mid=6,05$ lebih besar dari t-tabel $=2,045$. Hal ini menunjukan bahwa hipotesis nihil $\left(\mathrm{H}_{0}\right)$ ditolak dan hipotesis alternatif $\left(\mathrm{H}_{1}\right)$ diterima. Hasil ini menunjukan bahwa penerapan latihan goal setting dan visualisasi dapat meningkatkan motivasi pemain Daksina Futsal Academy.
\end{abstract}

Kata Kunci: Goal Setting, Visualisasi, Motivasi.

\section{ABSTRACT}

The purpose of this study was to determine the effectiveness of goal setting and visualization exercises for increasing the motivation of Daksina Futsal Academy players. This research was conducted at Daksina Futsal Academy and the method used in this study was the one group experimental method with the technique of the initial, treatment, and end (pre-test post-test). This research was followed by 30 samples of Daksina Futsal Academy players. They were asked to answer the items of the research questionnaire statement of motivation after that followed the goal setting and visualization training materials for 5 sessions then were given back the questionnaire to conduct the final test.

Delivered about the average value $(X)$ of the results obtained at the initial test 85.23 and at the final test 92.87. From the average regarding the initial test and the final test Motivation Daksina Futsal Academy players, showed an increase in results obtained. From the results of data analysis obtained an average difference $(M D)$ of -7.63 with a standard deviation of difference (SDD) 6.80 standard error of average difference (SEMD) of 1.29 in subsequent calculations obtained a $t$-value of -6, 05 and t-table values with degrees of freedom (n-1) and a significant level $\alpha=0.05$ obtained 2.045. Value $\mid t$-count $\mid=6.05$ is greater than $t$-table $=$ 2.045. This shows that the null hypothesis $(\mathrm{HO})$ is rejected and the alternative hypothesis (HI) is 
accepted. These results indicate that the application of goal setting and visualization exercises can increase the motivation of Daksina Futsal Academy players.

\section{Keywords: Goal Setting, Visualization, Motivation.}

\section{PENDAHULUAN}

Saat ini olahraga futsal adalah olahraga yang sangat digemari oleh masyarakat Indonesia. Dari mulai anak usia dini, pelajar, mahasiswa sampai pegawai kantoran baik pria maupun wanita ikut memainkan olahraga ini. Dari fasilitasnya pun mengalami perkembangan, hampir di seluruh daerah di Indonesia sudah mempunyai fasilitas lapangan futsal. Lapangan futsal yang ada di Indonesia pun beragam, dari segi ukuran dan lantai yang digunakan. Untuk lapangan futsal dengan standar internasional setidaknya pada sisi lapangan memiliki panjang 38-42 meter, sedangkan untuk lebarnya sekitar 18-25 meter. Jenis lantai yang di gunakan juga banyak macamnya, diantaranya vinyl, parquette (kayu), rumput sintetis, semen, dan interlock. Beberapa daerah sudah mempunyai fasilitas lapangan berukuran standar internasional seperti di Tifosi Sport Centre Jakarta Timur dengan menggunakan lantai berbahan interlock.

Futsal merupakan olahraga permainan yang dimainkan oleh dua tim, yang masingmasing beranggotakan lima orang. Tujuannya adalah untuk memasukkan bola ke gawang lawan, dengan memanipulasi bola dengan kaki. Olahraga futsal merupakan modifikasi olahraga sepak bola yang dimainkan di dalam ruangan. Teknik dasar yang digunakan

pun hampir sama dengan sepakbola, perbedaannya pada ukuran lapangan yang lebih kecil.

Futsal tidak hanya memerlukan fisik yang kuat tetapi juga harus dibarengi dengan teknik, taktik maupun mental yang baik pula. Pemain futsal harus memiliki teknik dasar yang mumpuni, seperti mengumpan (passing), menerima (receiving), mengumpan lambung (chipping), menggiring (dribbling), menembak (shooting), dan menyundul (heading)(Andri Irawan,2009). Keterampilan dasar tersebut perlu didukung oleh kemampuan dasar lainnya. Adapun aspek-aspek latihan yang perlu dilatih secara seksama oleh atlet adalah latihan fisik, teknik, taktik dan mental.

Olahraga futsal saat ini telah mengalami perkembangan yang pesat, salah satunya di kalangan anak muda Indonesia. Hal ini ditandai dengan banyaknya kejuaraan-kejuaraan futsal antar usia muda dari mulai tingkat daerah sampai nasional. Oleh karena itu, banyak sekali bermunculan akademi futsal di Indonesia sebagai wadah untuk menyalurkan bakat para anak muda di bidang futsal.

Kejuaraan rutin antar usia di masingmasing wilayah pun makin banyak terselenggara. Tiap akademi berlombalomba untuk bisa menjuarai kejuaraan yang diselenggarakan. Hal itu di karenakan setiap pemain dari masing-masing tim futsal pasti akan merasakan kegembiraan yang luar biasa ketika bisa menjuarai suatu kejuaraan. Selain bisa merasakan euforia saat bisa menjuarai suatu kejuaraan, para pemain pun bisa ikut mengharumkan nama akademi masing-masing dan mereka juga akan mendapat apresiasi lebih dari orang tua serta teman-temannya. Meskipun tidak mudah untuk dapat meraih semua itu.

Penetapan tujuan (goal setting) merupakan salah satu bagian dari aspek yang penting diberikan kepada pemain. Goal setting akan memberikan gambaran bagi pemain tentang apa yang harus dicapainya. Goal setting merupakan salah satu fondasi yang baik untuk mencapai sukses dalam program latihan keterampilan mental (Komarudin, 2013). Dengan demikian, goal setting merupakan suatu kemampuan merancang atau menetapkan tujuan yang hendak dicapai. Menurut Ibrahim dan Komarudin beranggapan bahwa, "Istilah goal setting ini terdiri atas dua kata, yaitu goal berarti tujuan, dan setting berarti penetapan atau merancang. Jadi dengan demikian, istilah goal setting dapat diartikan sebagai suatu kemampuan merancang atau menetapkan sesuatu tujuan 
yang hendak dicapai oleh seseorang atau kelompok"(Ibrahim dan Komarudin, 2007).

Sering kali seorang pemain Daksina Futsal Academy tidak berlatih secara sungguh-sungguh atau kurang motivasi ketika berlatih. Hal ini disebabkan karena tidak ada tujuan yang jelas yang harus dicapai dari proses latihan. Harsono menjelaskan, "Menetapkan sasaran atau prognosis, dan mengajarkan kepada atlet bagaimana menetapkan sasaran-sasaran latihan adalah penting". Aspek lain yang juga penting dalam peningkatan olahraga prestasi yaitu motivasi. Motivasi diperlukan agar pemain yang terlibat dalam olahraga mau berlatih lebih keras dan lebih giat lagi. Alderman menyebutkan, "Bahwa tidak ada prestasi tanpa motivasi"(Husdarta,2010). Tanpa motivasi yang kuat, pemain tidak akan memiliki kemauan dan tidak akan memiliki prestasi yang tinggi karena untuk mencapai suatu prestasi yang tinggi, motivasi yang besar sangatlah dibutuhkan.

Husdarta menjelaskan, "Bahwa motivasi diartikan sebagai proses yang menggerakkan seseorang hingga berbuat sesuatu". Motivasi adalah energi psikologis yang bersifat abstrak. Locke, Latham mengemukakan bahwa, "Goal setting adalah sebuah teori motivasi yang secara efektif memberi energi kepada atlet untuk menjadi lebih produktif dan efektif".

Pelatih seharusnya berusaha keras untuk mengembangkan motivasi dalam diri setiap pemainnya yang akan bertahan lama dan akan memacu dirinya untuk lebih giat lagi dalam berlatih.

Saat ini media televisi di Indonesia sangat memperhatikan perkembangan futsal di negeri ini. Banyak pertandingan futsal profesional di tingkat nasional yang sudah ditayangkan oleh beberapa media televisi di Indonesia, contohnya Pro Futsal League. Pro Futsal League merupakan kejuaraan kasta tertinggi di Indonesia. Banyak pemain futsal terbaik di Indonesia yang bertanding pada kejuaraan itu seperti Bambang Bayu Saptaji, Sunny Rizky, Andri Kustiawan, Ardiansyah Runtuboy, dan Rio Pangestu yang juga merupakan punggawa dari Timnas Futsal Indonesia. Hal ini sangat berdampak positif bagi para pemain Daksina Futsal Academy. Karena dengan menyaksikan pertandingan Pro Futsal League di televisi, pemain Daksina Futsal Academy menjadi semakin memiliki keinginan untuk bisa bermain di kejuaraan kasta tertinggi di Indonesia tersebut. Dengan kata lain, dengan menyaksikan pertandingan Pro Futsal League di televisi, para pemain Daksina Futsal Academy telah melakukan latihan visualisasi.

Visualisasi merupakan salah satu bentuk latihan mental. Visualisasi adalah latihan jangka panjang yang dilakukan secara sistematis dan berkelanjutan untuk membentuk dan mengembangkan keterampilan mental tertentu (Tirto Apriyanto, 2017).

Berdasarkan pernyataan-pernyataan yang dikemukakan diatas maka penulis ingin meningkatkan motivasi pemain Daksina Futsal Academy dengan menerapkan latihan goal setting dan visualisasi.

\section{METODE PENELITIAN}

Sering terjadi bahwa data yang dikumpulkan ternyata tidak atau kurang berkaedah untuk keperluan analisis persoalan yang di hadapi. Untuk mengatasi hal ini, sebuah cara harus ditempuh yang dikenal dengan nama desain eksperimen. Yaitu suatu rancangan percobaan (dengan tiap langkah tindakan yang betul - betul terdefinisikan) berhubungan dengan atau diperlukan untuk persoalan yang sedang diteliti dapat dikumpulkan. Dengan kata lain, sebuah desain eksperimen merupakan langkah - langkah lengkap yang perlu diambil jauh sebelum eksperimen dilakukan agar data yang seharusnya diperlukan dapat diperoleh sehingga akan membawa kepada analisis objektif dan kesimpulan berlaku untuk persoalan yang sedang di bahas.

Terdapat beberapa bentuk desain eksperimen yang dapat digunakan dalam penelitian. Dalam penelitian ini peneliti menggunakan one-group pretest-posttest design. Karena peneliti memberikan tes awal berupa angket tentang motivasi, kemudian diberikan perlakuan melalui pemberian materi latihan goal setting dan latihan visualisasi, setelah itu di tes kembali tentang motivasi. Adapun desain penelitian ini dapat digambarkan sebagai berikut: 


\section{$\mathrm{O} 1 \longrightarrow \mathrm{X} \longrightarrow \mathrm{O} 2$}

Gambar 1. Desain Penelitian

Keterangan:

O1 = Nilai Pre - test (sebelum diberikan

perlakuan)

$\mathrm{X}=$ Perlakuan

$\mathrm{O} 2=$ Nilai Pos - test (setelah diberikan

perlakuan)

\section{INSTRUMEN PENELITIAN}

Instrumen yang digunakan untuk pengumpulan data dalam penelitian ini adalah dengan cara pengisian angket yang telah disiapkan oleh peneliti tentang motivasi dengan menggunakan skala likert.

Pemberian nilai jawaban pada setiap pernyataan atau butir - butir angket dengan kategori pilihan antara lain:

SS : Sangat Sesuai $=5$

$S$ : Sesuai $=4$

$\mathrm{R}: \mathrm{Ragu}-\mathrm{Ragu}=3$

TS : Tidak Sesuai $=2$

STS: Sangat Tidak Sesuai $=1$

\section{Pembuatan Kisi - Kisi Angket}

Pembuatan angket mengacu pada definisi operasional yang diambil dari 6 (Enam) aspek motivasi yang menunjang, yaitu: Amotivation, External Regulation, Introjected Regulation, Identified Regulation, Integrated Motivation, Intrinsic Motivation. Dengan menggunakan 6 (enam) aspek penilaian tersebut, peneliti akan dapat mengetahui penerapan goal setting dan visualisasi untuk meningkatkan motivasi pemain Daksina Futsal Academy.

Tabel 1. Kisi - Kisi Instrumen Motivasi

\begin{tabular}{|c|c|c|c|c|c|c|c|}
\hline \multirow[b]{2}{*}{$\begin{array}{l}\mathbf{N} \\
\mathbf{o}\end{array}$} & \multirow[b]{2}{*}{ Aspek } & \multirow[b]{2}{*}{$\begin{array}{l}\text { No. } \\
\text { Soal }\end{array}$} & \multicolumn{5}{|c|}{ Penilaian } \\
\hline & & & $\begin{array}{l}\mathbf{S} \\
\mathbf{T} \\
\mathbf{S}\end{array}$ & $\begin{array}{l}\mathbf{T} \\
\mathbf{S}\end{array}$ & $\mathbf{R}$ & $\mathbf{S}$ & $\begin{array}{l}\mathbf{S} \\
\mathbf{S}\end{array}$ \\
\hline 1 & $\begin{array}{c}\text { Amotivatio } \\
n\end{array}$ & $\begin{array}{c}5,12,1 \\
7,22\end{array}$ & 1 & 2 & 3 & 4 & 5 \\
\hline 2 & $\begin{array}{c}\text { External } \\
\text { Regulation }\end{array}$ & $\begin{array}{c}4,11,1 \\
9,24\end{array}$ & 1 & 2 & 3 & 4 & 5 \\
\hline 3 & $\begin{array}{l}\text { Introjected } \\
\text { Regulation }\end{array}$ & $\begin{array}{c}7,10,1 \\
6,23\end{array}$ & 1 & 2 & 3 & 4 & 5 \\
\hline 4 & $\begin{array}{l}\text { Identified } \\
\text { Regulation }\end{array}$ & $\begin{array}{c}3,8,15 \\
, 20\end{array}$ & 1 & 2 & 3 & 4 & 5 \\
\hline
\end{tabular}

\begin{tabular}{cccccccc}
\hline \multirow{2}{*}{5} & $\begin{array}{c}\text { Integrated } \\
\text { Motivation }\end{array}$ & $\begin{array}{c}2,9,13 \\
, 21\end{array}$ & 1 & 2 & 3 & 4 & 5 \\
\hline \multirow{2}{*}{6} & Intrinsic & $1,6,14$ & 1 & 2 & 3 & 4 & 5 \\
& Motivation &, 18 & 1 & 2 & 3 & 4 & \\
\hline
\end{tabular}

Instrumen penelitian yang digunakan dalam penelitian ini adalah untuk mengukur motivasi, berikut instrumen yang digunakan:

Instrumen yang digunakan untuk dapat melihat penerapan latihan goal setting dan visualisasi terhadap motivasi menggunakan sesi - sesi sebagai berikut:

Sesi ke-1 Perkenalan

1. Prolog coaching staff dengan memberikan arahan bahwa pelatihan harus diikuti seluruh pemain.

2. Perkenalan dengan Trainer/Peneliti.

3. Trainer/Peneliti memperkenalkan diri dan menjelaskan maksud dan tujuan peneliti sehingga ada lembar persetujuan dari atlet untuk mengikuti pelatihan.

4. Penjelasan tentang kesatuan jiwa dan raga. Atlet diminta menyanyikan lirik lagu Indonesia Raya "Bangunlah Jiwanya Bangunlah Badannya Untuk Indonesia Raya".

Pemberian kuesioner (pengambilan data pre-test).

Sesi ke-2 Pelatihan Goal Setting

1. Prolog dari trainer (Cerita).

2. Penjelasan tentang goal setting (Pengertian, Tujuan dan Manfaatnya).

3. Menumbuhkan motivasi dengan cara membuat "Pohon Harapan".

Sesi ke-3 Pelatihan Visualisasi

1. Prolog tentang visualisasi (Pengertian, Tujuan dan Manfaatnya).

2. Menayangkan highlight tentang pemain futsal di liga profesional.

Sesi ke-4 Pelatihan Visualisai (Lanjutan)

1. Diskusi dan review latihan visualisasi sebelumnya.

2. Menayangkan highlights tetang pemain futsal tim nasional di pertandingan internasional.

Sesi ke-5 Penutup

1. Diskusi dan feedback tentang pelatihan yang telah dilakukan.

2. Pemberian kuesioner (post - test).

Alat - alat yang dibutuhkan: 
- Pulpen

- Form Tes

- Dokumentasi Foto

- Video cuplikan pertandingan futsal

- Proyektor

\section{HASIL PENELITIAN}

Deskripsi data pada penelitian ini meliputi nilai tertinggi, nilai rata-rata, standar deviasi, standar error, distribusi frekuensi, serta histogram dari masingmasing variable, berikut data lengkapnya

Tabel 2. Deskripsi data penelitian motivasi pemain Daksina Futsal Academy

\begin{tabular}{lll}
\hline Variabel & Awal & Akhir \\
\hline Nilai tertinggi & 95 & 106 \\
\hline Nilai Terendah & 74 & 79 \\
\hline Rata-rata & 85,23 & 92,87 \\
\hline Standar deviasi & 6,21 & 6,94 \\
\hline Standar error & 1,15 & 1,28 \\
\hline
\end{tabular}

Data Hasil Tes Awal Motivasi

Data yang terkumpul mengenai motivasi didapati pada tes awal menunjukan rentangan nilai tertinggi 95 dan nilai terendah 74 dengan rata-rata 85,23 , standar deviasi (SD) sebesar 6,21, standar error mean $\left(\mathrm{SE}_{\mathrm{M}}\right)$ sebesar 1,15 (lihat lampiran). Hal tersebut dapat terlihat pada distribusi frekuensi dan histogram berikut:

Tabel 3. Distribusi Frekuensi Tes Awal Motivasi

\begin{tabular}{ccccc}
\hline $\begin{array}{c}\text { N } \\
\text { o }\end{array}$ & $\begin{array}{c}\text { Kelas } \\
\text { Interval }\end{array}$ & $\begin{array}{c}\text { Nilai } \\
\text { Tenga } \\
\text { h }\end{array}$ & $\begin{array}{c}\text { Frekuen } \\
\text { si } \\
\text { Absolut }\end{array}$ & $\begin{array}{c}\text { Frekue } \\
\text { nsi } \\
\text { Relatif }\end{array}$ \\
\hline 1 & $74-77$ & 75,5 & 4 & $13 \%$ \\
\hline 2 & $78-81$ & 79,5 & 6 & $20 \%$ \\
\hline 3 & $82-85$ & 83,5 & 6 & $20 \%$ \\
\hline 4 & $86-89$ & 87,5 & 4 & $13 \%$ \\
\hline 5 & $90-93$ & 91,5 & 7 & $23 \%$ \\
\hline 6 & $94-97$ & 95,5 & 3 & $10 \%$ \\
\hline & Jumlah & & 30 & $100 \%$ \\
\hline
\end{tabular}

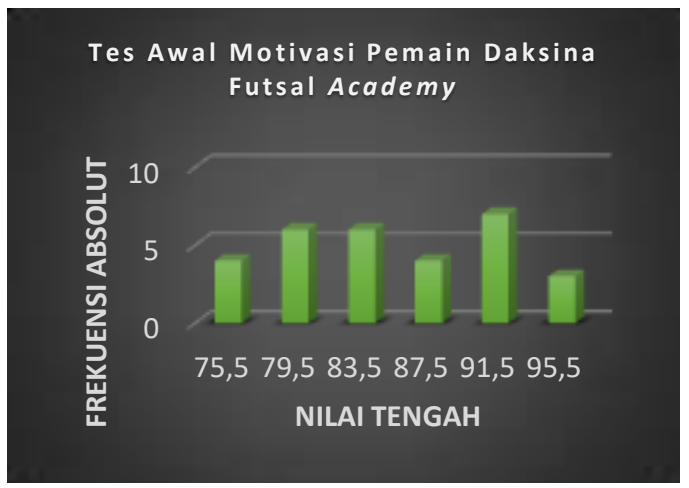

Gambar 2. Data Hasil Tes Akhir Motivasi

Data yang terkumpul mengenai motivasi pemain Daksina Futsal Academy didapati pada tes akhir menunjukan rentangan nilai tertinggi 106 dan nilai terendah 79 dengan rata-rata 92,87, standar deviasi (SD) sebesar 6,94, standar error mean $\left(\mathrm{SE}_{\mathrm{M}}\right)$ sebesar 1,28.

Tabel 4. Distribusi Frekuensi Tes Akhir Motivasi

\begin{tabular}{ccccc}
\hline $\begin{array}{l}\text { N } \\
\text { o. }\end{array}$ & $\begin{array}{l}\text { K.Inte } \\
\text { rval }\end{array}$ & $\begin{array}{c}\text { N.Te } \\
\text { ngah }\end{array}$ & $\begin{array}{c}\text { Frek. } \\
\text { Absolut }\end{array}$ & $\begin{array}{c}\text { Frek. } \\
\text { Relatif }\end{array}$ \\
\hline 1 & $79-83$ & 81 & 4 & $13 \%$ \\
\hline 2 & $84-88$ & 86 & 5 & $17 \%$ \\
\hline 3 & $89-93$ & 91 & 7 & $23 \%$ \\
\hline 4 & $94-98$ & 96 & 6 & $20 \%$ \\
\hline 5 & $99-103$ & 101 & 6 & $20 \%$ \\
\hline 6 & $\begin{array}{c}104- \\
108\end{array}$ & 106 & 2 & $7 \%$ \\
\hline & Jumlah & & 30 & $100 \%$ \\
\hline
\end{tabular}

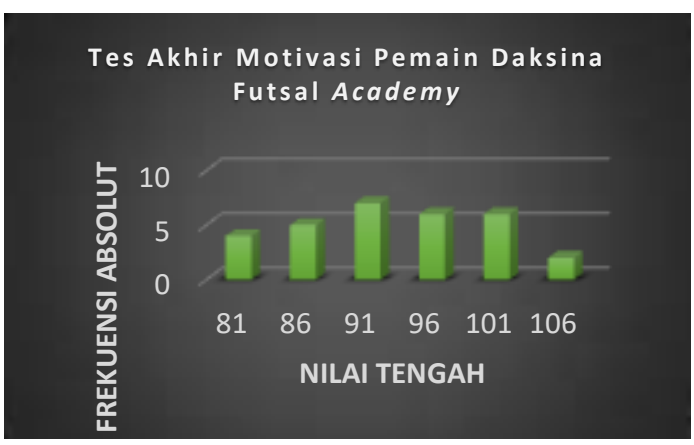

Gambar 3. Pengujian Hipotesis

Disampaikan tentang nilai rata-rata $(\bar{X})$ dari hasil yang didapatkan pada tes awal 85,23 dan pada tes akhir 92,87. Dari rata-rata mengenai tes awal dan tes akhir motivasi pemain Daksina Futsal Academy, menunjukan adanya peningkatan hasil yang 
didapat. Dari hasil analisis data diperoleh selisih rata-rata $\left(\mathrm{M}_{\mathrm{D}}\right)-7,63$ dengan standar deviasi perbedaan $\left(\mathrm{SD}_{\mathrm{D}}\right)$ 6,80 standar error perbedaan rata-rata $\left(\mathrm{SE}_{\mathrm{MD}}\right)$ 1,29 dalam perhitungan selanjutnya diperoleh nilai thitung sebesar $-6,05$ dan nilai t-tabel dengan derajat kebebasan (n-1) dan taraf signifikan $\alpha=0,05$ didapat sebesar 2,045. Nilai $\mid \mathrm{t}-$ hitung $\mid=6,05$ lebih besar dari ttabel $=2,045$. Hal ini menunjukan bahwa hipotesis nihil $\left(\mathrm{H}_{0}\right)$ ditolak dan hipotesis alternatif $\left(\mathrm{H}_{1}\right)$ diterima.

\section{PEMBAHASAN}

Tabel 5. Persentase Enam Aspek Motivasi

\begin{tabular}{|c|c|c|c|c|c|c|}
\hline \multirow[t]{2}{*}{$\begin{array}{l}\mathbf{N} \\
\mathbf{0}\end{array}$} & \multirow{2}{*}{$\begin{array}{c}\text { Aspek } \\
\text { Motiva } \\
\text { si }\end{array}$} & \multicolumn{2}{|c|}{$\begin{array}{c}\text { Rata- } \\
\text { rata } \\
\text { Aspek } \\
\text { Motivasi }\end{array}$} & \multicolumn{2}{|c|}{$\begin{array}{c}\text { Persentase } \\
\text { Aspek } \\
\text { Motivasi }\end{array}$} & \multirow[t]{2}{*}{$\begin{array}{c}\text { Has } \\
\text { il }\end{array}$} \\
\hline & & $\begin{array}{c}\text { Aw } \\
\text { al }\end{array}$ & $\begin{array}{l}\text { Ak } \\
\text { hir }\end{array}$ & $\begin{array}{c}\text { Awa } \\
1\end{array}$ & $\begin{array}{l}\text { Akh } \\
\text { ir }\end{array}$ & \\
\hline 1 & $\begin{array}{c}\text { Amotiv } \\
\text { ation }\end{array}$ & $\begin{array}{c}9,0 \\
3 \\
\end{array}$ & $\begin{array}{c}9,8 \\
3 \\
\end{array}$ & $\begin{array}{c}45,1 \\
7 \% \\
\end{array}$ & $\begin{array}{c}49,1 \\
7 \% \\
\end{array}$ & $\begin{array}{l}4,0 \\
0 \% \\
\end{array}$ \\
\hline 2 & $\begin{array}{c}\text { Externa } \\
1 \\
\text { Regulat } \\
\text { ion }\end{array}$ & $\begin{array}{l}12, \\
97\end{array}$ & $\begin{array}{l}14, \\
50\end{array}$ & $\begin{array}{c}64,8 \\
3 \%\end{array}$ & $\begin{array}{l}72,5 \\
0 \%\end{array}$ & $\begin{array}{l}7,6 \\
7 \%\end{array}$ \\
\hline 3 & $\begin{array}{l}\text { Introrej } \\
\text { ected } \\
\text { Regulti } \\
\text { on }\end{array}$ & $\begin{array}{l}15 \\
00\end{array}$ & $\begin{array}{l}16 \\
50\end{array}$ & $75 \%$ & $\begin{array}{l}82,5 \\
0 \%\end{array}$ & $\begin{array}{l}7,5 \\
\%\end{array}$ \\
\hline 4 & $\begin{array}{l}\text { Identifi } \\
\text { ed } \\
\text { Regulat } \\
\text { ion }\end{array}$ & $\begin{array}{l}16 \\
67\end{array}$ & $\begin{array}{l}17 \\
63\end{array}$ & $\begin{array}{c}83,3 \\
3 \%\end{array}$ & $\begin{array}{l}88,1 \\
7 \%\end{array}$ & $\begin{array}{l}4,8 \\
4 \%\end{array}$ \\
\hline 5 & $\begin{array}{l}\text { Integrat } \\
\text { ed } \\
\text { regulati } \\
\text { on }\end{array}$ & $\begin{array}{l}15 \\
47\end{array}$ & $\begin{array}{l}16 \\
67\end{array}$ & $\begin{array}{l}77,3 \\
3 \%\end{array}$ & $\begin{array}{l}83,3 \\
3 \%\end{array}$ & $\begin{array}{l}6,0 \\
0 \%\end{array}$ \\
\hline 6 & $\begin{array}{c}\text { Intrinsic } \\
\text { motivati } \\
\text { on }\end{array}$ & $\begin{array}{l}16 \\
10\end{array}$ & $\begin{array}{l}17 \\
73\end{array}$ & $\begin{array}{c}80,5 \\
0 \%\end{array}$ & $\begin{array}{l}88,6 \\
7 \%\end{array}$ & $\begin{array}{l}8,1 \\
7 \%\end{array}$ \\
\hline
\end{tabular}

perhitungan Jumalh rata-rata aspek motivasi dibagi jumlah skor dengan nilai tertinggi pernyataan yakni 5. Dapat diintepretasikan bahwa pada aspek amotivation mengalami peningkatan sebesar $4,00 \%$, aspek external regulation mengalami peningkatan sebesar 7,67\%, aspek introrejected regulation mengalami peningkatan sebesar $7,5 \%$, aspek identified regulation mengalami peningkatan sebesar $4,84 \%$, integrated regulation mengalami peningkatan sebesar $6,00 \%$, dan aspek intrinsic motivation mengalami peningkatan sebesar $8,17 \%$.

Jika dilihat dari keenam aspek tersebut, aspek motivasi yang mengalami peningkatan tertinggi adalah aspek intrinsic motivation sebesar $8,17 \%$ dan peningkatan tertinggi kedua ada pada aspek external regulation sebesar 7,67\%, sedangkan aspek introrejected regulation dan integrated regulation berada pada posisi ketiga dan keempat dengan peningkatan sebesar 7,50\% dan 6,00\%, aspek identified regulation berada pada posisi kelima dengan peningkatan sebesar $4,84 \%$, dan aspek motivasi yang mengalami peningkatan terendah adalah aspek amotivation dengan peningkatan sebesar 4,00\%.

Jadi dapat disimpulkan bahwa peningkatan yang cukup tinggi terjadi pada tiga aspek yakni intrinsic motivation, external regulation, dan introrejected regulation. Dan tiga aspek motivasi integrated regulation, identified regulation, dan amotivation mengalami sedikit peningkatan. Penelitian ini seharusnya dilakukan dalam waktu yang lebih lama agar peningkatan motivasi lebih meningkat dan dalam pelatihan goal setting dan visualisasi di perlukan.

\section{KESIMPULAN}

Berdasarkan penelitian yang dilakukan, maka dapat disimpulkan bahwa penerapan latihan goal setting dan visualisasi efektif untuk meningkatkan motivasi pemain Daksina Futsal Academy setelah diberikan pelatihan goal setting dan visualisasi yang dilakukan oleh peneliti.

\section{DAFTAR PUSTAKA}

Andri Irawan. 2009. Teknik Dasar Modern Futsal, Jakarta: Pena Pundi Aksara.

Komarudin. 2013. Psikologi Olahraga. Bandung: Remaja Rosdakarya.

Ibrahim dan Komarudin. 2007. Psikologi Kepelatihan. Bandung: FPOK UPI. 
Penerapan Latihan Goal Setting Dan Visualisasi Terhadap Peningkatan Motivasi Pemain

Harsono. 1988. Coaching dan Aspek Aspek Psikologis dalam Coacing. Jakarta: CV. Tambak Kusuma.

Husdarta. 2010. Psikologi Olahraga. Bandung: Alfabeta.

Tirto Apriyanto. 2017. Psikologi Olahraga: Student Handbook. Gowa: EduTama.

Mallet Cliff et. al., "Sport Motivation Scale6 (SMS-6): a revised six-factor sport motivation scale". September 2007 